\title{
Acute and Massive Aortic Thrombosis and Embolic Occlusion in a Patient with COVID-19: A Case Report
}

\author{
Seyedjavad Davarisani ${ }^{1}$, Javad Koushki ${ }^{2}$, Saeed Moghaddamzade ${ }^{2}$, Hamzeh Sherafati ${ }^{2}$, Mehdi \\ Jamalinik ${ }^{3}$, Ali Abedi ${ }^{4}$, Fatemeh Salaripour ${ }^{5}$ and Maryam Sarkardeh ${ }^{6, *}$ \\ ${ }^{1}$ Student Research Committee, Sabzevar University of Medical Sciences, Sabzevar, Iran \\ ${ }^{2}$ Department of Surgery, Imam Reza Hospital, Mashhad University of Medical Sciences, Mashhad, Iran \\ ${ }^{3}$ Department of Nursing, Tabas Branch, Islamic Azad University, Tabas, Iran \\ ${ }^{4}$ Department of Nursing, Esfarayen Faculty of Medical Sciences, Esfarayen, Iran \\ ${ }^{5}$ Department of Radiology, Mother Hospital, Ramhormoz, Iran \\ ${ }^{6}$ Surgical Oncology Research Center, Faculty of Medicine, Mashhad University of Medical Sciences, Mashhad, Iran \\ "Corresponding author: Surgical Oncology Research Center, Faculty of Medicine, Mashhad University of Medical Sciences, Mashhad, Iran. Email: sarkardehm@mums.ac.ir
}

Received 2020 October 31; Revised 2021 August 08; Accepted 2021 September 08.

\begin{abstract}
A 73-year-old man with a history of COVID-19 infection from two weeks ago was referred to the Emergency Department with a complaint of colicky and generalized abdominal pain in addition to prior respiratory symptoms. High-resolution Computed Tomography (HRCT) displayed the typical signs of COVID-19 pneumonia. Initially, laboratory tests showed increased C-reactive protein and severe leukocytosis. Because of generalized abdominal pain, spiral abdominal and pelvic CT scans were done, which showed massive irregular and free-floating aortic thrombosis from the carina site to the Superior Mesenteric Artery (SMA) detachment, indicative of acute and life-threatening thrombosis. Filling defects were seen in the middle and distal part of the splenic artery, indicating the embolic occlusion of the splenic artery. The patient was admitted to the Intensive Care Unit (ICU), and he became a candidate for conservative treatment because of the wide extension of thrombosis. Therefore, we should pay more attention to the indirect signs of thrombosis in patients with COVID-19 infection with gastrointestinal symptoms and consider anticoagulant therapy for high-risk patients with COVID-19. The unique feature of our case was acute and extensive arterial thrombosis.
\end{abstract}

Keywords: Abdominal Pain, Aortic Thrombosis, COVID-19

\section{Introduction}

Gastrointestinal symptoms including nausea, vomiting, constipation, diarrhea, and poor appetite have been reported in up to $39 \%$ of Coronavirus Disease 2019 (COVID19)-infected patients (1). These findings have been confirmed in other studies $(2,3)$. Recently, new evidence suggests a link between gastrointestinal symptoms and complications such as coagulopathy in COVID-19-infected patients (4-6). New studies have shown that venous and arterial thromboembolic disease may occur in COVID-19 patients due to excessive inflammation, hypoxia, and immobilization, and Diffuse Intravascular Coagulation (DIC) (79).

In this study, clinical features, lab tests, and CT scan findings of acute and massive aortic thrombosis were reported in a 73-year-old patient who was infected by COVID19 and referred to the hospital with gastrointestinal symptoms.

\section{Case Presentation}

A 73-year-old man with a history of ischemic heart disease (IHD) was referred to the Emergent Department (ED) because of generalized abdominal pain with anorexia starting one day ago. Two weeks ago, he presented to the hospital with a complaint of fever and acute dyspnea, and after doing a chest CT scan and PCR, the diagnosis of COVID-19 was made for him. After control of his respiratory symptoms, he was discharged without any anticoagulation drug.

Initially, when he returned with abdominal pain, the hemodynamic status was stable (BP: 145/90 mm $\mathrm{Hg}$ and pulse rate was $95 \mathrm{bpm}$ ), and the patient showed symptoms of acute respiratory insufficiency (RR: 21, O2Sat: 88\%). Laboratory tests showed increased C-reactive protein $(110 \mathrm{mg} / \mathrm{L})$ and severe leukocytosis (WBC count $28.2 \times 1000 / \mathrm{mm}^{3}$ ), but prothrombin time (PT), activated partial thromboplastin time (aPTT), international normalized ratio (INR) and platelet count were within the normal limits. Blood 
gas analysis showed no acidosis. The patient's alanine transaminase (ALT) enzyme was excessively increased, but aspartate transaminase (AST) was within the normal range. The PCR test for COVID-19 was still positive on this admission (Table 1). Electrocardiography (ECG) was normal with sinusoidal rhythm and no evidence of atrial fibrillation (AF) rhythm. Also, echocardiography was performed, with no evidence of clot in the heart, and ejection fraction was in the normal range (50\%).

high-resolution computed tomography (HRCT) was performed for him due to respiratory symptoms, which displayed typical signs of COVID-19 pneumonia (Figure 1). Due to the generalized abdominal pain, the patient underwent spiral abdominal, and pelvic CT scans with and without intravenous injection and oral contrast agent. The CT scan report showed an irregular and free-floating aortic thrombosis from the carina site to the superior mesenteric artery (SMA) detachment site (Figures 2A, B, C, and F) indicative of acute and life-threatening thrombosis because of the high possibility of systemic embolization. No sign of significant atherosclerosis was seen in the aorta. Filling defects were seen in the middle and distal part of the splenic artery, indicating embolic occlusion of the splenic artery (Figures 2D and E). Also, multiple wedge-shaped lowdensity areas of the spleen were evident (classic appearance of massive splenic infarct). There were evident embolic filling defects of the left renal artery and the right renal arterial branches, along with heterogeneous contrast enhancement of both kidneys with triangular parenchymal areas of lower attenuation because of renal ischemia. After doing the CT scan, the patient was admitted to the Intensive Care Unit (ICU). A vascular surgery consult was applied, which showed the patient was a candidate for conservative treatment. Based on the vascular surgeon's opinion, surgery was not possible for him because of massive aortic thrombosis. Also, a hematologic consult was performed for the evaluation of the causes of the hypercoagulative state. We checked tumor markers (CEA, CA19-9, and PSA), all of which were normal. Because of the patient's condition, which was in the inflammatory phase due to COVID-19 infection, hyper-coagulative state tests were not reliable, and we were recommended to do these tests after the patient's recovery. After about two weeks of conservative management with anticoagulant therapy and remission of respiratory symptoms, the patient was discharged with oral anticoagulants (warfarin $5 \mathrm{mg}$ daily) and good general condition. After discharge, he did not return to the clinic for follow-up; so, we called him after two months and asked about his condition. He was in a good condition with no problem.

\begin{tabular}{|c|c|c|}
\hline & $\begin{array}{l}\text { Admission (May 20, } \\
\text { 2020) }\end{array}$ & $\begin{array}{c}\text { Discharge (May 31, } \\
\text { 2020) }\end{array}$ \\
\hline $\begin{array}{l}\text { White blood cell } \\
\text { count }\left(\text { per } \mathrm{mm}^{3} \text { ) }\right.\end{array}$ & 28200 & 13000 \\
\hline $\begin{array}{l}\text { Red blood cell count } \\
\left.\text { (per } \mathrm{mm}^{3}\right)\end{array}$ & 5.54 & 4.68 \\
\hline $\begin{array}{l}\text { Fasting blood sugar } \\
(\mathbf{m g} / \mathbf{L})\end{array}$ & 263 & 156 \\
\hline Urea & 33 & 43 \\
\hline Total neutrophils & 67.7 & 56.5 \\
\hline Total lymphocytes & 27.9 & 39.7 \\
\hline $\begin{array}{l}\text { Platelet count (per } \\
\text { mm }^{3} \text { ) }\end{array}$ & 251 & 361 \\
\hline $\operatorname{Hemoglobin}(\mathrm{g} / \mathrm{L})$ & 15.4 & 12.5 \\
\hline $\begin{array}{l}\text { Alanine } \\
\text { aminotransferase } \\
(\mathrm{U} / \mathrm{L})\end{array}$ & 237 & 34 \\
\hline $\begin{array}{l}\text { Aspartate } \\
\text { aminotransferase } \\
\text { (U/L) }\end{array}$ & 34 & 21 \\
\hline Creatinine $(\mu \mathrm{mol} / \mathrm{L})$ & 0.8 & 0.7 \\
\hline $\begin{array}{l}\text { C-reactive protein } \\
(\mathrm{mg} / \mathrm{L})\end{array}$ & 110 & - \\
\hline $\mathrm{Na}$ & 134 & 140 \\
\hline $\mathbf{K}$ & 3.8 & 3.6 \\
\hline Bill-direct & 0.5 & 0.5 \\
\hline Bill-indirect & 0.6 & 0.3 \\
\hline ESR & 59 & - \\
\hline pH & 7.52 & - \\
\hline $\mathrm{PaO}_{2}$ & 133.4 & - \\
\hline $\mathrm{PaCO}_{2}$ & 22.4 & - \\
\hline $\mathrm{HCO}_{3}$ & 18.3 & - \\
\hline Amylase & 81 & - \\
\hline Lipase & 35 & - \\
\hline TPI & $8 / 4(\mathrm{nl})$ & - \\
\hline $\begin{array}{l}\text { Prothrombin time } \\
(\text { PT) (s) }\end{array}$ & 14.7 & 26.5 \\
\hline $\begin{array}{l}\text { Activated partial- } \\
\text { thromboplastin } \\
\text { time }(\text { PTT })(s)\end{array}$ & 26 & 39 \\
\hline INR & 1.28 & 2.3 \\
\hline $\begin{array}{l}\text { PCR quality for } \\
\text { COVID-19 }\end{array}$ & Positive & - \\
\hline
\end{tabular}

\section{Discussion}

As known, COVID-19 has misleading symptoms, and it is associated with a wide range of symptoms (10) and complications, including severe distress (11), sepsis (12), septic 


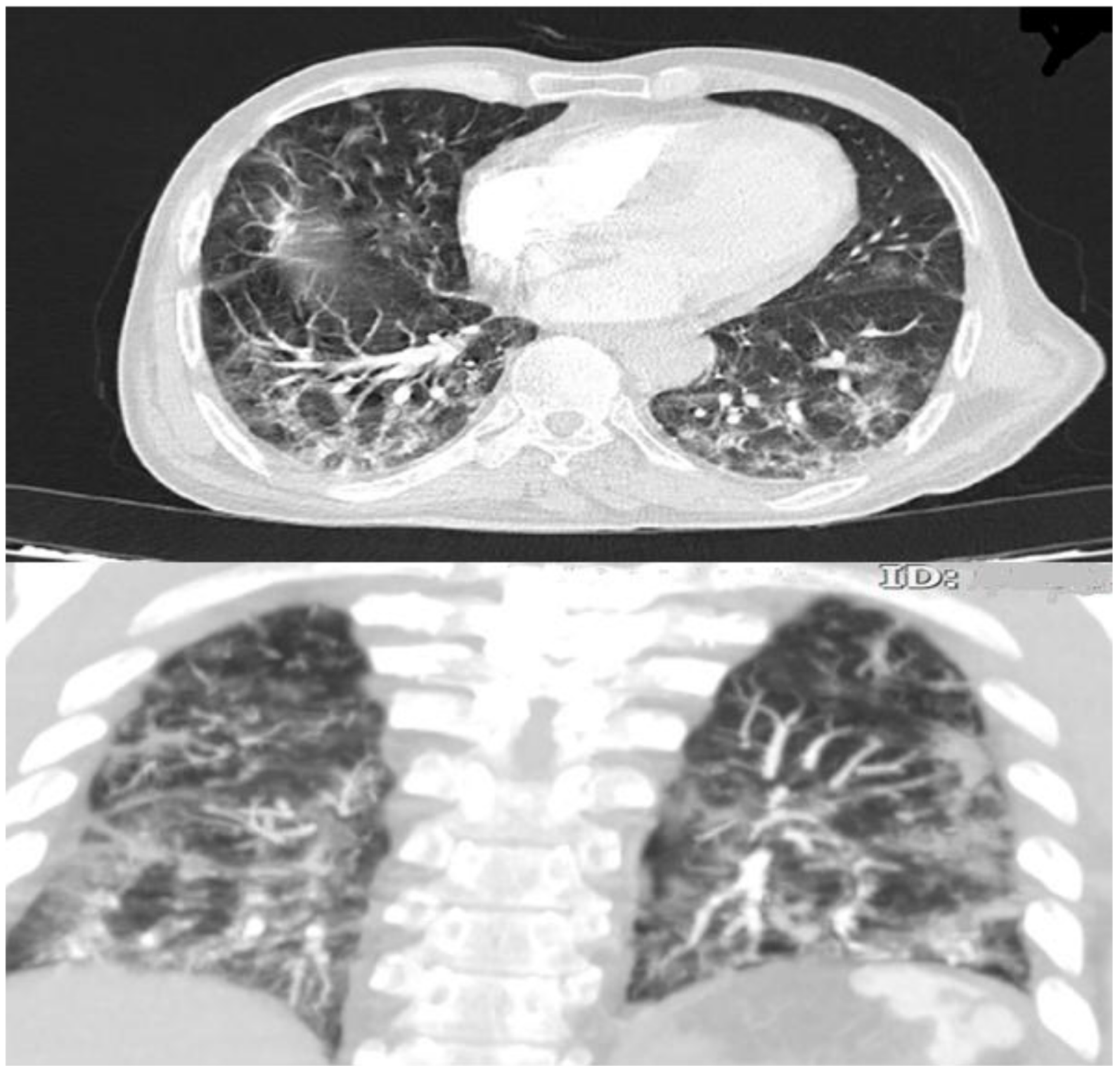

Figure 1. Chest computed tomography (CT) of the patient

shock (12), and coagulopathy (8). Coagulopathy commonly happens in sepsis, and it may be a side effect of COVID19 (13). This coagulopathy can lead to outcomes including pulmonary thromboembolism $(4,14)$. Ignat et al. reported small bowel ischemia because of mesenteric and portal vein thrombosis in patients infected with SARS-CoV-2 (15). Similarly, Vulliamy et al. reported acute aorto-iliac mesenteric arterial thrombosis in patients infected with COVID19 (6). Also, de Barry et al. reported arterial and venous abdominal thrombosis in a 79-year-old woman with COVID-19 pneumonia (16). The unique feature of our case was acute and massive aortic thrombosis with embolic occlusion of the splenic artery, the left renal artery, and the right renal arterial branches, which may be due to coronavirus infection and its side effects.

\subsection{Conclusions}

The present and previous studies show that the side effects of COVID-19 infection are arterial and venous abdominal thrombosis. Therefore, COVID-19 patients who present with gastrointestinal symptoms such as nausea, diarrhea, poor appetite, and abdominal pain should be paid more 

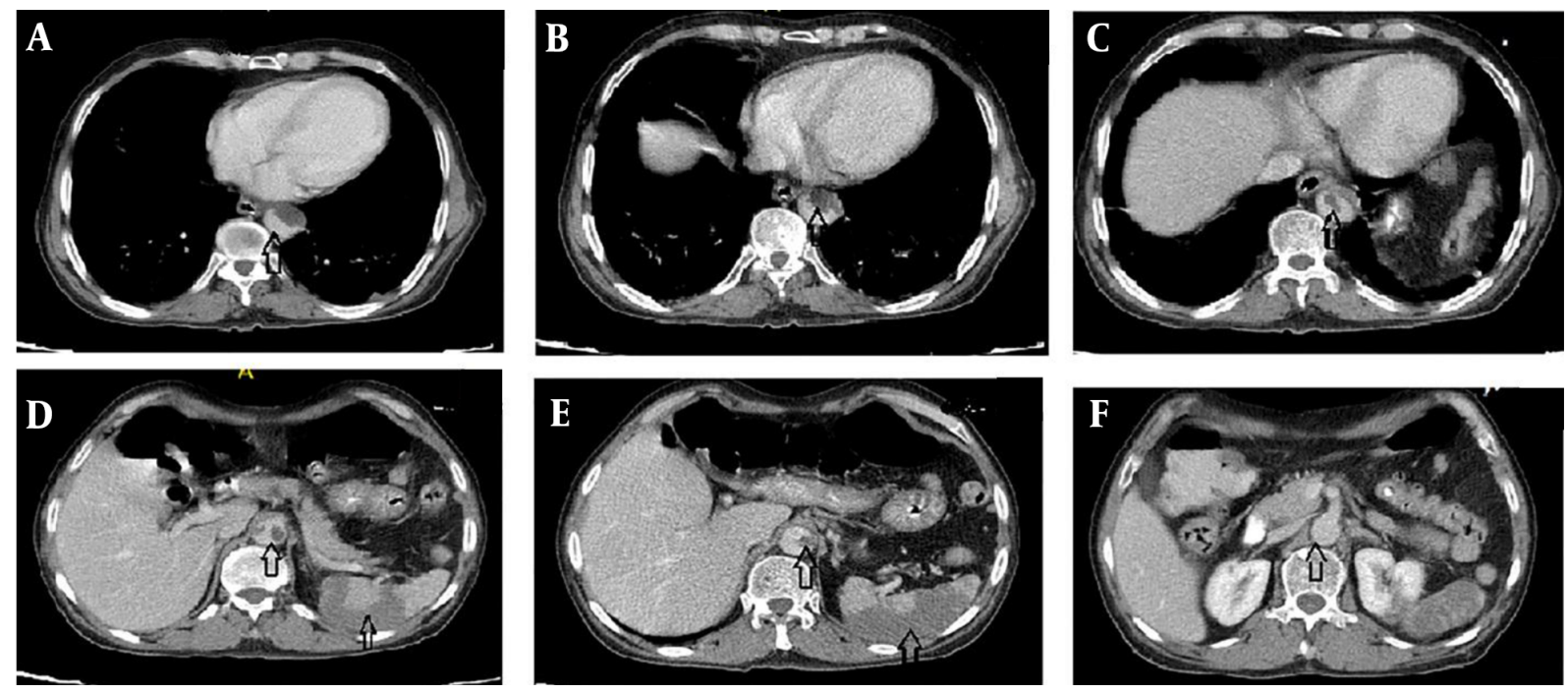

Figure 2. Spiral abdominal and pelvic CT scans of the patient

attention to concerning arterial and venous abdominal thrombosis.

\section{Footnotes}

Authors' Contribution: Study concept and design: M.S; Drafting of the manuscript: M.S, J.D, J.K, S.M, H.SH, M.J, A.A, and F.S; Critical revision of the manuscript for important intellectual content: M.S and J.D.

Conflict of Interests: The authors declare that there are no conflicts of interest.

Ethical Approval: All aspects of ethics for this article were done, and all information about the patient is confidential.

Funding/Support: No funding was received for this study. Informed Consent: Written informed consent was obtained from the patient.

\section{References}

1. Zhang JJ, Dong X, Cao YY, Yuan YD, Yang YB, Yan YQ, et al. Clinical characteristics of 140 patients infected with SARS-CoV-2 in Wuhan, China. Allergy. 2020;75(7):1730-41. doi: 10.111//all.14238. [PubMed: 32077115].

2. Xiao F, Tang M, Zheng X, Liu Y, Li X, Shan H. Evidence for gastrointestinal infection of SARS-CoV-2. Gastroenterology. 2020;158(6):1831-1833 e3. doi: 10.1053/j.gastro.2020.02.055. [PubMed: 32142773]. [PubMed Central: PMC7130181].

3. Hajifathalian K, Mahadev S, Schwartz RE, Shah S, Sampath K, Schnoll-Sussman F, et al. SARS-COV-2 infection (coronavirus disease 2019) for the gastrointestinal consultant. World J Gastroenterol. 2020;26(14):1546-53. doi: 10.3748/wjg.v26.i14.1546. [PubMed: 32327904]. [PubMed Central: PMC7167410].

4. Fabre O, Rebet O, Carjaliu I, Radutoiu M, Gautier L, Hysi I. Severe acute proximal pulmonary embolism and COVID-19: A word of caution. Ann Thorac Surg. 2020;110(5):e409-11. doi: 10.1016/j.athoracsur.2020.04.005. [PubMed: 32305287]. [PubMed Central: PMC7162739].

5. Kaur P, Qaqa F, Ramahi A, Shamoon Y, Singhal M, Shamoon F, et al. Acute upper limb ischemia in a patient with COVID-19. Hematol Oncol Stem Cell Ther. 2020. doi: 10.1016/j.hemonc.2020.05.001. [PubMed: 32405288]. [PubMed Central: PMC7219365].

6. Vulliamy P, Jacob S, Davenport RA. Acute aorto-iliac and mesenteric arterial thromboses as presenting features of COVID-19. Br J Haematol. 2020;189(6):1053-4. doi: 10.1111/bjh.16760. [PubMed: 32353183]. [PubMed Central: PMC7267618].

7. Guan WJ, Ni ZY, Hu Y, Liang WH, Ou CQ, He JX, et al. Clinical characteristics of coronavirus disease 2019 in China. $N$ Engl J Med. 2020;382(18):1708-20. doi: 10.1056/NEJMoa2002032. [PubMed: 32109013]. [PubMed Central: PMC7092819].

8. Wang D, Hu B, Hu C, Zhu F, Liu X, Zhang J, et al. Clinical characteristics of 138 hospitalized patients with 2019 novel coronavirusinfected pneumonia in Wuhan, China. JAMA. 2020;323(11):1061-9. doi: 10.1001/jama.2020.1585. [PubMed: 32031570]. [PubMed Central: PMC7042881].

9. Zhou F, Yu T, Du R, Fan G, Liu Y, Liu Z, et al. Clinical course and risk factors for mortality of adult inpatients with COVID-19 in Wuhan, China: a retrospective cohort study. Lancet. 2020;395(10229):1054-62. doi: 10.1016/s0140-6736(20)30566-3.

10. Li Q, Guan X, Wu P, Wang X, Zhou L, Tong Y, et al. Early transmission dynamics in Wuhan, China, of novel coronavirus-infected pneumonia. N Engl J Med. 2020;382(13):1199-207. doi: 10.1056/NEJMoa2001316. [PubMed: 31995857]. [PubMed Central: PMC7121484].

11. Matthay MA, Aldrich JM, Gotts JE. Treatment for severe acute respiratory distress syndrome from COVID-19. Lancet Respir Med. 2020;8(5):433-4. doi: 10.1016/S2213-2600(20)30127-2. [PubMed: 32203709]. [PubMed Central: PMC7118607].

12. Cascella M, Rajnik M, Aleem A, Dulebohn SC, Di Napoli R. Features, evaluation, and treatment of coronavirus (COVID-19). Treasure Island (FL): StatPearls; 2021.

13. Rotzinger DC, Beigelman-Aubry C, von Garnier C, Qanadli SD. Pulmonary embolism in patients with COVID-19: Time to change the paradigm of computed tomography. Thromb Res. 2020;190:58-9. doi: 10.1016/j.thromres.2020.04.011. [PubMed: 32302782]. [PubMed Central: PMC7151364]. 
14. Cellina M, Orsi M, Bombaci F, Sala M, Marino P, Oliva G. Favorable changes of CT findings in a patient with COVID-19 pneumonia after treatment with tocilizumab. Diagn Interv Imaging. 2020;101(5):323-4 doi: 10.1016/j.diii.2020.03.010. [PubMed: 32278585]. [PubMed Central: PMC7270926].

15. Ignat M, Philouze G, Aussenac-Belle L, Faucher V, Collange O, Mutter D, et al. Small bowel ischemia and SARS-CoV-2 infection: an un derdiagnosed distinct clinical entity. Surgery. 2020;168(1):14-6. doi: 10.1016/j.surg.2020.04.035. [PubMed: 32473831]. [PubMed Central: PMC7198136].

16. de Barry O, Mekki A, Diffre C, Seror M, El Hajjam M, Carlier RY. Arterial and venous abdominal thrombosis in a 79-year-old woman with COVID-19 pneumonia. Radiol Case Rep. 2020;15(7):1054-7. doi: 10.1016/j.radcr.2020.04.055. [PubMed: 32351657]. [PubMed Central: PMC7188660]. 